Construction \& Building Materials

Elsevier Editorial system(tm) for

Manuscript Draft

Manuscript Number: CONBUILDMAT-D-18-04329R1

Title: Effects of non-stationary stray current on carbon steel buried pipelines under cathodic protection

Article Type: Research Paper

Keywords: carbon steel; cathodic protection; electrochemistry; pipeline; polarization; stray current.

Corresponding Author: Professor Marco Ormellese, Prof.

Corresponding Author's Institution: Politecnico di Milano

First Author: Marco Ormellese, Prof.

Order of Authors: Marco Ormellese, Prof.; Silvia Beretta, Eng.; Fabio Brugneti; Andrea Brenna, Eng.

Abstract: DC stray currents may cause severe corrosion on buried carbon steel pipelines even if in cathodic protection. According to

international standard anodic interference is unacceptable if the IR-free potential is more positive than the protection potential (-0.85 V CSE). But, duration and magnitude of the anodic peak is not defined. The criterion appears to be too restrictive if short periods of anodic interference are established. This paper deals with the study of the effects of anodic interference on carbon steel in cathodic protection in soil-simulating environment in the presence of DC interference at varying peak current density and duration. 
Dear Editor,

I am enclosing herewith a manuscript entitled:

\section{"Effects of non-stationary stray current on carbon steel buried pipelines under cathodic protection"}

The manuscript has been prepared according to the "Construction and Building Materials" guidelines.

The article evaluates the effect of stray current originating from DC electrical systems on the corrosion of buried metal structures, as carbon steel pipes, tanks or vessels, under cathodic protection (CP). DC interference sources include high voltage transmission lines, electrical traction and power networks, and cathodic protection systems too. Depending on stray current source, stationary or fluctuating interference may occur on steel structures even under cathodic protection condition. Nowadays, international standards establish the general principles for the identification and control of DC interference, mainly based on potential and voltage gradients measurements over a $24 \mathrm{~h}$ period. Generally, in order to assess the corrosion to which any metal structure is exposed as a result of stray current, the positive (anodic) potential shift of the affected structure shall be considered. As regards carbon steel under cathodic protection condition, anodic DC interference is considered unacceptable if the IR-free potential is more positive than the protection potential provided by standard (-0.850 V CSE in aerobic condition). But, duration and magnitude of the anodic peak should be taken into account to evaluate the actual corrosion effects of the interference on protected steel. In fact, the -0.850 V CSE criterion appears to be too restrictive if short periods of anodic interference are alternated with the re-establishment of the protection condition with the beneficial increase of the pipe-to-soil alkalinity due to the cathodic current. This paper deals with the study of the effects of anodic interference on buried carbon steel structures in cathodic protection condition. Weight loss tests were carried out on cathodically protected steel specimens in soilsimulating environment in the presence of DC interference varying anodic current density (from 0.1 to $10 \mathrm{~A} / \mathrm{m}^{2}$ ) and duration of the interference peaks, applied for $3600 \mathrm{~s}$ daily overall. IR-free potential was also monitored.

All authors of this research paper have directly participated in the design, execution, or analysis of this study; all authors have read and approved the final version submitted. The authors declare no competing financial interest. No specific funding source has supported this research. The paper is original and not considered for publication elsewhere. Please consider it for publishing in your Journal.

Thank you for kind attention.

Best regards,

Marco Ormellese

\section{Corresponding author}

Prof. Marco Ormellese, PhD

Politecnico di Milano - Department of Chemistry, Materials and Chemical Engineering "G.

Natta", Via Mancinelli 7, 20131 Milan, Italy

e-mail marco.ormellese@polimi.it

Tel. +390223993118 


\section{Declaration}

On behalf of all the authors of the submitted paper "Effects of non-stationary stray current on carbon steel buried pipelines under cathodic protection", I declare there are no conflict of interest in publishing the work.

Best regards

The Corresponding author

Prof. Marco Ormellese

Politecnico di Milano

Department of Chemistry, Materials and Chemical Engineering "G. Natta" Via Mancinelli 7, 20131 Milan, Italy

e-mail marco.ormellese@polimi.it

Tel. $\quad+390223993118$ 


\section{COMMENTS TO REVIEWERS}

First, we would like to thank the reviewers for their precious comments, very helpful to improve the quality of the paper. Hereafter the answers to the comments.

Changes in the manuscript are highlighted in yellow.

\section{REVIEWER \#1}

Introduction: Is there any relevant work reported previously on non-stationary DC interference on buried pipelines or other structures? If yes, please include to provide an insight into this interesting phenomenon.

Literature and introduction section has been improved according to the reviewer suggestion.

The authors should provide a diagram detailing the setup of the steel specimen under $\mathrm{CP}$, while under interrupted DC interference. It would be mandatory to have the diagram as the electrical circuit to enable both CP and DC is critical to the reliability of the measured data.

A scheme of the electrical circuit has been added and described in the manuscript as requested.

p. 5: The cell contained "silica sand and a soil simulating solution". Please give details of the sands, i.e., size, shape, rounded or unrounded, content, etc.

Rounded sand ( $4 \mathrm{~mm}$ max diameter) has been used. Details have been reported in the manuscript

p. 7, Eq. (2): During two months of testing, it is expected that corrosion products would generate and deposit on the steel surface. The corrosion products can affect the actual current density flowing through the specimen when the authors use applied anodic current divide the specimen area. How were the authors quantify the actual current density applied on the specimen with corrosion products?

At the end of the test, when samples were removed from the cell, corrosion products were present, mostly on tests performed at $10 \mathrm{~A} / \mathrm{m} 2$. In any case, they do not create any sort of electrical insulation. Corrosion product were conductive and do not form in two months sufficient insulation in order to reduce the net surface. Therefore, we assumed constant in time the surface exchanging current with soil. Accordingly, the current density was assumed to be constant in such a period.

Fig. 5: What is the reason that the potential cannot maintain constant as a function of time?

Tests have been performed in galvanostatic control. Therefore, potential may show some oscillations. The main reasons are diffusion of oxygen and temperature. In any case, the fluctuation associated to any tests, represented by different symbol, are acceptable. In fact, the main point was to guarantee a good cathodic protection level, according to standard. 
Figs. 6-9: Why the two curves in each figure have different start potentials? Cannot start at the same level?

The difference in start potentials is due to the local difference of each cell. Since we perform test in galvanostatic control mode, it is not possible to assume a constant potential in all the cells. What is important is that in all the tested condition the steady stable potential is in the range $-0.85 /-1.2 \mathrm{~V}$ CSE

Fig. 12: The explanation is nice in terms of the passivity-activity transition under DC application. It would be better if the authors provide direct evidence to support the proposed time \% for passivity/corrosion in Table 2. If not, the explanation is speculative only.

We thank the reviewer to appreciate our interpretation.

The percentage values presented in Table 2 have been estimated by dividing the period in passivation, as defined in Figure 12, by the total duration of a peak. For example, if we consider test at $C P 1 \mathrm{~A} / \mathrm{m} 2$, peak total duration 1 minute, we have a time in passivation of $37 \mathrm{~s}$, which corresponds to the $62 \%$ of one minute.

The explanation of the \% calculation been added in the manuscript.

\section{REVIEWER \#2}

On page 3 , line 63 , it is not accurate to say "the anodic site is located under the substation", which is determined by the location of coating defects, soil resistivity and other factors.

A better explanation is given in the manuscript.

Besides, in the sentence of "In spite of the limited duration, the effects may be severe due to the high circulating current." What is the limited duration? Please give more explanation.

More information are given in the manuscript.

Because the work of this paper focused on the effects of non-stationary stray current, the introduction on stationary interference (from line 48 line 57 ) should be simplified.

Text has been simplified.

More introduction on the dynamic characteristics of stray current from DC traction systems and existing research work on the corrosion behavior under non-stationary stray current should be added in the paper. A more completed literature review is needed.

Literature and introduction section has been improved according to the reviewer suggestion. 
On page 6, line 120, please give more detailed introduction on how to get IR-free potential, by instant-off method or only placing reference electrode close to the specimens?

IR-free potential was measured by means of a Luggin capillary, so placing the reference electrode as close as possible to the specimens. Text has been modified.

From Figure 6 to Figure 8, "in the presence of $10 \mathrm{~A} / \mathrm{m} 2 \mathrm{DC}$ interference, a strong increase of potential was recorded: maximum recorded value was close to +1.2V CSE" (Page 10, line 175), please give more detailed introduction on the measurement of IR-free potential when the interference is applied and analyze the ohmic drop error existed in the case of $10 \mathrm{~A} / \mathrm{m} 2 \mathrm{DC}$ interference. Although a luggin capillary filled with the test solution was placed as close as possible to the exposed carbon steel surface, when the DC interference current density is as large as $10 \mathrm{~A} / \mathrm{m2}$, the ohmic drop produced near the specimen could not be neglected unless other method such as instant off method was used to eliminate the IR drop.

Thank you to the reviewer; this is a good point to be clarified.

We do not use instant off readings. In any case, the ohmic drop could be roughly estimated by the following equation: $\mathrm{IR}=$ resistivity $\mathrm{x}$ distance $\mathrm{x}$ current density. Considering resistivity less than $20 \mathrm{ohm} \mathrm{m}$, distance 1 $\mathrm{mm}$, the ohmic drop is $2 \mathrm{mV}$ if $0,1 \mathrm{~A} / \mathrm{m} 2$ are applied (negligible), $20 \mathrm{mV}$ in the case of $1 \mathrm{~A} / \mathrm{m} 2$ (negligible) and $200 \mathrm{mV}$ in the case of current density $10 \mathrm{~A} / \mathrm{m} 2$. In the last case, some ohmic drop is present in the reading; in any case, the potential trend recorded is not strongly affected by this ohmic drop contribution and the comments are still valid.

An explanation has been introduced in the manuscript at the end of potential profile description.

On page 11, line 212, "Indeed, supposing a carbon steel anodic Tafel slope of about $60 \mathrm{mV} / \mathrm{decade}$, the maximum potential shift should be in the range of $0.3 \mathrm{~V}$ at the highest anodic DC current density." Please provide the anodic polarization curve of the specimen in the experimental environment.

A Tafel curve has been performed and the graph has been reported in this section.

Please give more evidence to verify there exist passive film on the specimen in the presence of severe anodic current density $(10 \mathrm{~A} / \mathrm{m} 2)$, such as the product analyses of the film or reaction phenomenon during the interference.

We described this point in the discussion section, describing the reaction phenomenon during both $\mathrm{CP}$ (effect of alkalinity) and DC interference at any level. We will take into consideration the reviewer suggestion regarding the chemical analysis. We will consider this part in a further paper. 
- The alkalinity produced during CP reduces the DC interference effect

- Anodic reaction initially causes the neutralization of electrolyte alkalinity

- The anodic potential shift is higher than what expected by Tafel law

- Potential peak cannot be used as parameter to evaluate the risk of DC interference

- DC peak intensity and duration are the key parameters. 


\section{Effects of non-stationary stray current on carbon steel buried pipelines under}

\section{2 cathodic protection}

4 Marco Ormellese $^{\mathrm{a},{ }^{,},}$, Silvia Beretta ${ }^{\mathrm{a}}$, Fabio Brugnetti ${ }^{\mathrm{b}}$, Andrea Brenna $^{\mathrm{a}}$

6 a Dipartimento di Chimica, Materiali e Ingegneria Chimica, "G. Natta”, Politecnico di Milano, Via Luigi

7 Mancinelli 7, 20131 Milan, Italy.

$8{ }^{\mathrm{b}}$ APCE, Associazione per la Protezione dalle Corrosioni Elettrolitiche, Via Maastricht 1, 20097 San Donato

9 Milanese, Italy.

11 " Corresponding author:

12 Prof. Marco Ormellese,

13 Dipartimento di Chimica, Materiali e Ingegneria Chimica, "G. Natta", Politecnico di Milano, Via Luigi Mancinelli 147,20131 Milan, Italy.

15 Tel +390223993118 e-mail marco.ormellese@polimi.it

\section{Abstract}

18 DC stray currents may cause severe corrosion on buried carbon steel pipelines even if in cathodic

19 protection. According to international standard anodic interference is unacceptable if the IR-free

20 potential is more positive than the protection potential (-0.85 V CSE). But, duration and magnitude

21 of the anodic peak is not defined. The criterion appears to be too restrictive if short periods of anodic

22 interference are established. This paper deals with the study of the effects of anodic interference on

23 carbon steel in cathodic protection in soil-simulating environment in the presence of DC interference

24 at varying peak current density and duration.

26 Keywords: carbon steel, cathodic protection, electrochemistry, pipeline, polarization, stray current. 


\section{Introduction}

29 Buried carbon steel pipelines are typically protected against corrosion by combining an external

30 polymeric coating and cathodic protection (CP). The latter is an electrochemical technique used to

31 prevent and control corrosion, acting by lowering the potential of the protected structure (called the

32 cathode) by supplying an external DC current. The cathodic polarization favors oxygen reduction

33 reaction at the metal surface with a consequent positive alkalization at the pipe-to-soil interface.

34 ISO 15589-1 [2] defines CP criteria: if on-potential, i.e. potential measured during CP, is lower than

35 free corrosion potential, the general criterion is applied; if IR-free potential, i.e. potential measured

36 during CP without any ohmic drop contribution, is lower than the protection potential level reported

37 in the same standard, also CP effectiveness is assured. In this case, carbon steel corrosion rate is

38 negligible, lower than $10 \mu \mathrm{m} / \mathrm{y}$.

39 The presence of stray current may cause severe damages on buried structures, even under CP

40 condition [3-10]. Generally, electric interference is defined as any alteration of the electric field

41 caused by a foreign structure. If the foreign body is a conductor, as a buried steel pipe, the current

42 is intercepted and can provoke corrosion where the current is released from the metal to soil (anodic

43 interference) [1].

44 Both DC and AC interference may cause corrosion on pipeline buried in soil. As regards the

45 presence of $\mathrm{AC}$ interference, there is lack of agreement about the CP criteria to control interference

46 and about the correct procedure to monitor buried pipeline potential [11-14].

47 DC interference can be stationary or non-stationary, depending on interference source. Stationary

48 interference can take place when the structure is immersed in a stationary electric field generated

49 for instance by a CP system with the ground bed close to the structure. An example is reported in

50 Figure 1: the non-protected pipeline suffers anodic interference, then corrosion, at the crossing

51 point. Corrosion can be very severe since the anodic current is typically released at coating defects

52 or holidays. A local current density as high as $10 \mathrm{~A} / \mathrm{m}^{2}$ is possible, then producing a corrosion rate

53 of about $10 \mathrm{~mm} / \mathrm{y}$. 


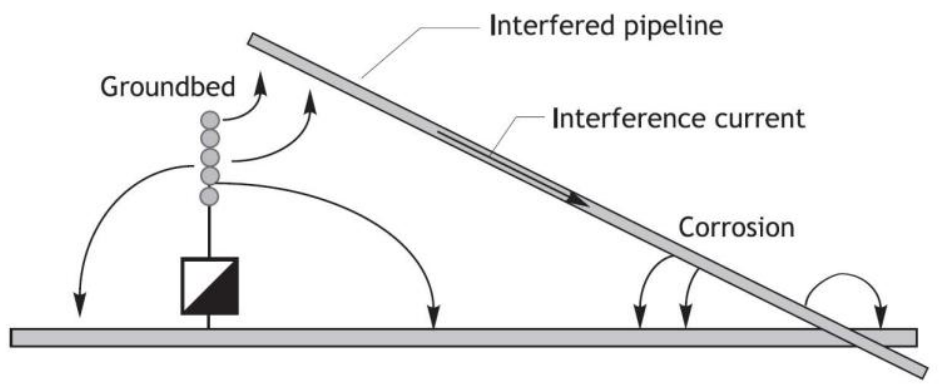

Figure 1 - Scheme of stationary interference between two crossing pipelines

57 Non-stationary interference takes place when the electric field is variable, as in the typical case of

58 stray currents dispersed by DC traction systems (Figure 2). Interference occurs only during the

59 transit of the train. The current supplied by the positive pole of the substation flows in the aerial

60 cable and then on the train through the pantograph. In the return path, part of the current flows into

61 the ground, interfering pipelines parallel to the rail. Some pipeline areas absorb current, showing a

62 cathodic behavior, some other release current, assuming an anodic behavior and then corroding.

63 Anodic site is typically located in proximity of the substation, as all the current has to return to the

64 negative pole of the substation. The exact location is determined by the presence of defects in the

65 pipeline coating, by the local soil resistivity and by all the factors that affect it, i.e. soil composition,

66 pipeline backfill, water retention. The duration of the interfering period is limited, and it is equal to

67 the time the train circulates between two subsequent substations, typically some minutes, according

68 to the train velocity. Despite the limited time, the corrosion effect may be severe as the circulating

69 current is high, promoting typically a local anodic current density about $1-10 \mathrm{~A} / \mathrm{m}^{2}$.

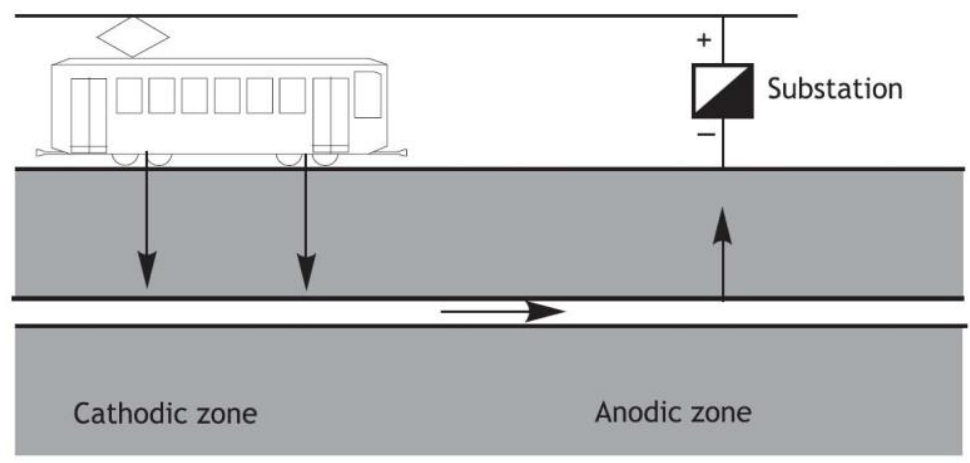

71 Figure 2 - Scheme of non-stationary interference caused by stray current dispersed by a DC transit system 
Allahkaram [7] investigated the effects of stray currents generated by DC traction system on cathodically protected gas pipelines in the city of Tehran. Results showed that when the distance between rails and pipeline exceed $1.5 \mathrm{~km}$ the interference effect is negligible. At a lower distance, parallel pipes are more affected than crossed aligned pipes. Besides pipe position, soil resistivity plays a significant role. Birbilis [8] demonstrated the importance of soil resistivity. Even under very severe anodic exposure (anodic polarization up to $0 \mathrm{~V}$ CSE), carbon steel corrosion is limited to relatively modest values in high-resistivity soil (more than $200 \Omega \mathrm{m}$ ). In low-resistivity soil (lower than $40 \Omega \mathrm{m}$ ), corrosion rapidly accelerated. Birbilis pointed out that corrosion from anodic transients is not cumulative and do not follow the values predicted from Faraday's law; he hypnotized the beneficial effects of CP persist for some time even after the removal of protection. Hou [9] obtained the same conclusion. Moreover, he defined a critical anodic transient duration, about 15 minutes long, which is a sort of 'safe' period in any single anodic transients during which corrosion in negligible on cathodically protected buried steel. He also concluded that the passive condition promoted by CP are not completely destroyed by DC interference, provided the amplitude and duration are below critical values. Same consideration are reported in [10]. $\mathrm{CP}$ criteria and mitigation measurements in the presence of DC interference are available for several years [2, 15-16]. The European Standard EN 50162 "Protection against corrosion by stray current from direct current systems" describes appropriate measures, which can be applied to interfered DC systems and to structures exposed to stray current corrosion [15]. As regard protection criteria, anodic interference on freely corroding metallic structures is considered acceptable if the positive potential shift (excluding IR-drop) is lower than $20 \mathrm{mV}$ for steel. For

94 structures under CP, anodic interference is considered unacceptable if the IR-free potential is outside the potential range provided by ISO 15589-1, i.e. if the IR-free potential does not match the -0.850 V CSE criterion [2, 17-19].

Nevertheless, this protection criterion in the presence of non-stationary interference seems to be too restrictive considering that short periods of interference (in the order of a few seconds up to maximum of a few minutes during the transit of the train) are alternated with the re-establishment of 
$100 \mathrm{CP}$ condition. It follows that in a continuous digital potential recorder over a $24 \mathrm{~h}$ period, the

101 protection criterion will be not matched corresponding to the anodic potential peaks more positive 102 than $-0.850 \mathrm{~V}$ CSE, regardless the duration and intensity of interference.

103 This paper deals with the study of the effect of DC anodic non-stationary interference on buried 104 carbon steel structures under CP condition. In particular, tests aim to verify the acceptability of a 1053600 s daily DC interference on corrosion of cathodically protected carbon steel. Weight loss tests

106 were carried out on steel specimens in soil-simulating environment varying the anodic current 107 density (from 0.1 to $10 \mathrm{~A} / \mathrm{m}^{2}$ ) and the duration pf the peak (from 1 minute up to 1 hour). Preliminary 108 results were presented elsewhere [20].

\section{2. Materials and methods}

110 Laboratory tests were carried out on carbon steel specimens type UNS G10180 (grade L360 111 according to EN 10208 [21]), equivalent to API 5L X52 (according to API 5L [22]). Chemical 112 composition (wt \%) is $0.25 \mathrm{C}, 1.4 \mathrm{Mn}, 0.45 \mathrm{Si}, 0.0025 \mathrm{P}, 0.1 \mathrm{~V}$ and Fe balance. After preparation 113 and cleaning operations according to ASTM G1 [23], specimens were placed in a PVC cylindrical 114 watertight sample holder (Figure 3), exposing a circular net surface of $1 \mathrm{~cm}^{2}$ to the electrolyte, in 115 order to simulate a coating defect of a steel pipe. A stainless steel screw on the top of the sample 116 holder provides the electrical contact with the sample. In order to prevent galvanic coupling effects, 117 a glass tube was placed to insulate the electrical contact.

118 Samples were placed in a cylindrical cell (diameter $150 \mathrm{~mm}$; height $200 \mathrm{~mm}$ ) containing silica sand 119 (grounded spherical sand, $4 \mathrm{~mm}$ maximum diameter, $1 \mathrm{~kg}$ for each cell) and a soil-simulating 120 solution: $1 \mathrm{~g} / \mathrm{L} \mathrm{Na}_{2} \mathrm{SO}_{4}$ and $0.2 \mathrm{~g} / \mathrm{L} \mathrm{NaCl}$. Soil resistivity was less than $20 \Omega \mathrm{m}$. A Luggin capillary, 121 filled with the same test solution, was place as close as possible to the exposed carbon steel 122 surface (distance $1 \mathrm{~mm}$ ) in order to eliminate the ohmic drop contribution during potential reading 123 (Figure 4). 


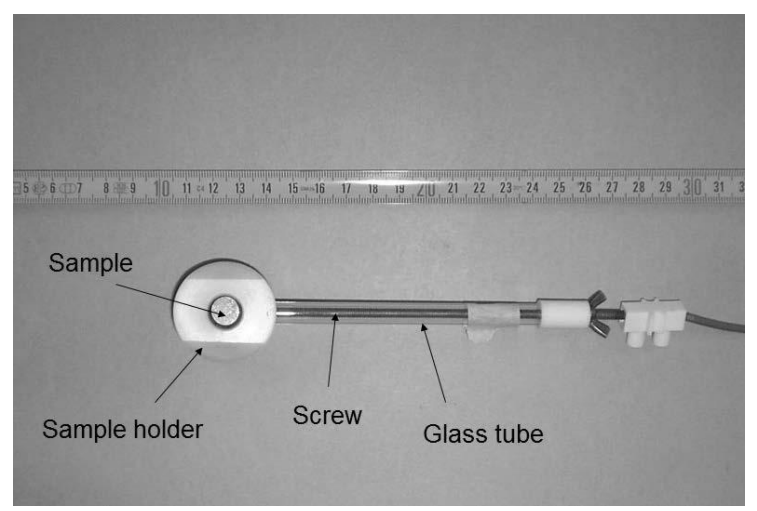

Figure 3 - Carbon steel specimen

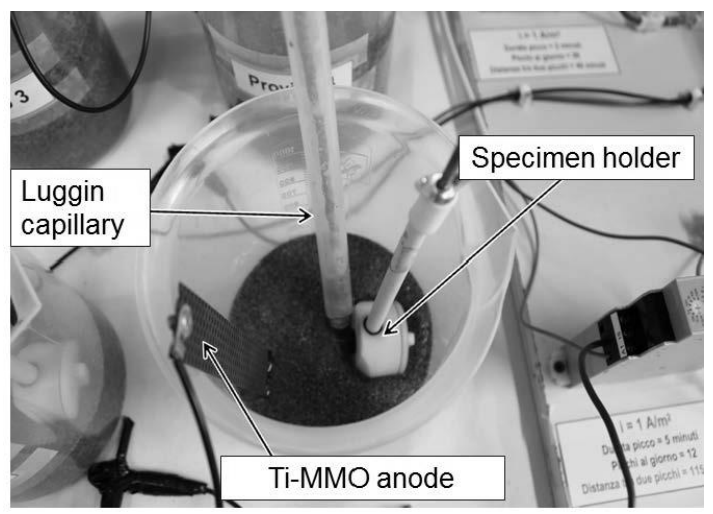

Figure 4 - Cell assembly

129 Figure 5 shows a schematic representation of the electrical circuit. Carbon steel specimens were 130 cathodically polarized by means of a CP feeder through an activated mixed-metal-oxide titanium 131 insoluble anode (Ti-MMO anode) placed in the same cell. A second DC feeder applied anodic 132 interference. A programmable automatic switcher has been used to change the polarization mode 133 from cathodic protection to interference according to the testing condition (see Table 1). A $10 \Omega$ 134 shunt was place in series to the sample to measure the flowing current. 


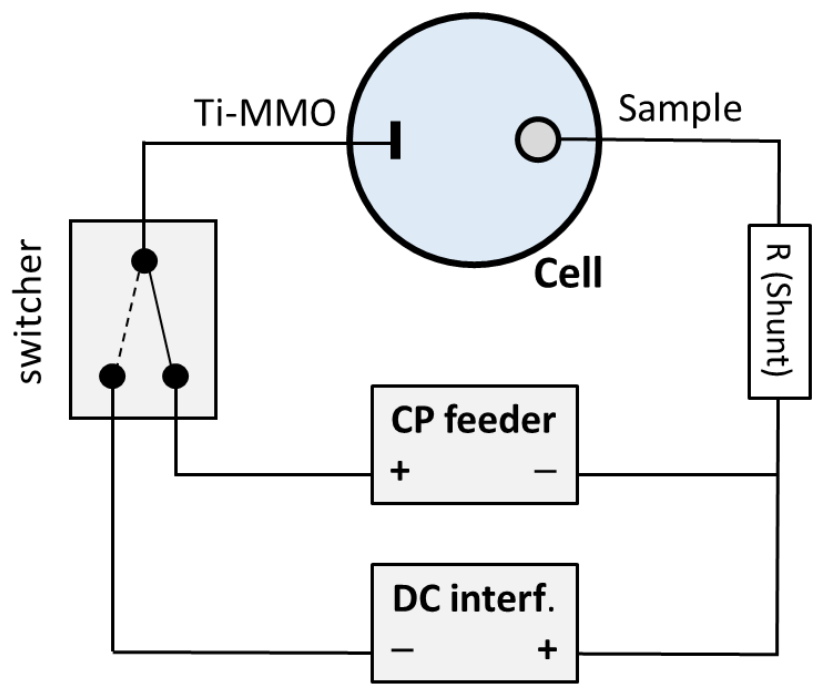

Figure 5 - Schematic representation of the electrical circuit used to supply cathodic protection and to apply DC interference

140 Firstly, CP was applied for two weeks, without any DC interference. Protection potential was 141 monitored and adjusted in the range $-0.85 \mathrm{~V} /-1.25 \mathrm{~V}$ CSE. Then anodic interference was applied.

142 Three anodic current densities were considered: $0.1,1.0$, and $10 \mathrm{~A} / \mathrm{m}^{2}$. Duration of a single DC 143 peak is reported in Table 1. The total duration of the interference was $1 \mathrm{~h} /$ day. In the presence of $1440.1 \mathrm{~A} / \mathrm{m}^{2}$ anodic interference, a single peak $1 \mathrm{~h}$ long was applied.

145 Potential was daily measured by means of a high impedance voltmeter $(200 \mathrm{M} \Omega)$ and an external $146 \mathrm{Cu} / \mathrm{CuSO}_{4, \text { sat }}$ reference electrode (CSE, +0.32 V SHE, Standard Hydrogen Electrode) using the the 147 Luggin capillary. Once a week potential was recorded by means of a data-logger (frequency 0.5 $148 \mathrm{~Hz})$

Table 1 - Duration of DC anodic peak and total number of peak per day

\begin{tabular}{cccc}
\hline $\begin{array}{c}\text { Peak duration } \\
\text { (minutes) }\end{array}$ & $\begin{array}{c}\text { Total number of DC } \\
\text { anodic peak per day }\end{array}$ & $\begin{array}{c}\text { Total peak duration } \\
\text { (minutes) }\end{array}$ & $\begin{array}{c}\text { CP duration between } \\
\text { two DC peaks (minutes) }\end{array}$ \\
\hline 1 & 60 & 60 & 23 \\
\hline 2 & 15 & 60 & 46 \\
\hline 5 & 12 & 60 & 115 \\
\hline 60 & 1 & 60 & $1380(23 \mathrm{~h})$ \\
\hline
\end{tabular}


152 After two months testing, samples were extracted from the cell and corrosion products were

153 removed by means of a chemical cleaning at room temperature with hydrochloric acid 1:1 inhibited

154 with $3.5 \mathrm{~g} / \mathrm{L}$ hexamethylenetetramine, according to ASTM G1 [23]. Corrosion rate, CR, was

155 calculated by means of weight loss measurement:

156

157

$$
C R=\Delta W /(S \cdot t \cdot \gamma)
$$

158

159 where $\Delta W$ is weight loss, $S$ is the exposed surface of the sample $\left(1 \mathrm{~cm}^{2}\right), \gamma$ is carbon steel density

160 and $t$ the duration of the tests.

161 Practical corrosion rate was compared with the theoretical steel dissolution rate, $C R_{\mathrm{th}}$, calculated by

162 Faraday's law:

163

164

$$
C R_{t h}=\frac{A W}{2 \cdot F \cdot \gamma} \cdot i
$$

165 where $A W$ is iron atomic weight $(55.8 \mathrm{~g} / \mathrm{mol}), F$ is Faraday constant $(96485 \mathrm{C})$ and $i$ is the applied 166 anodic current density.

\section{3. Results}

$168 \quad 3.1$ Potential monitoring

169 IR-free protection potential was measured every day before applying DC interference. Figure 6

170 shows protection potential reading during all the tests. Different symbols refer to different cells. The

171 potential in CP condition was in the fixed range $-0.85 \mathrm{~V}$ to $-1.25 \mathrm{~V}$ CSE. Accordingly, for all

172 specimens, the $-0.85 \mathrm{~V}$ CSE criterion is always matched. 


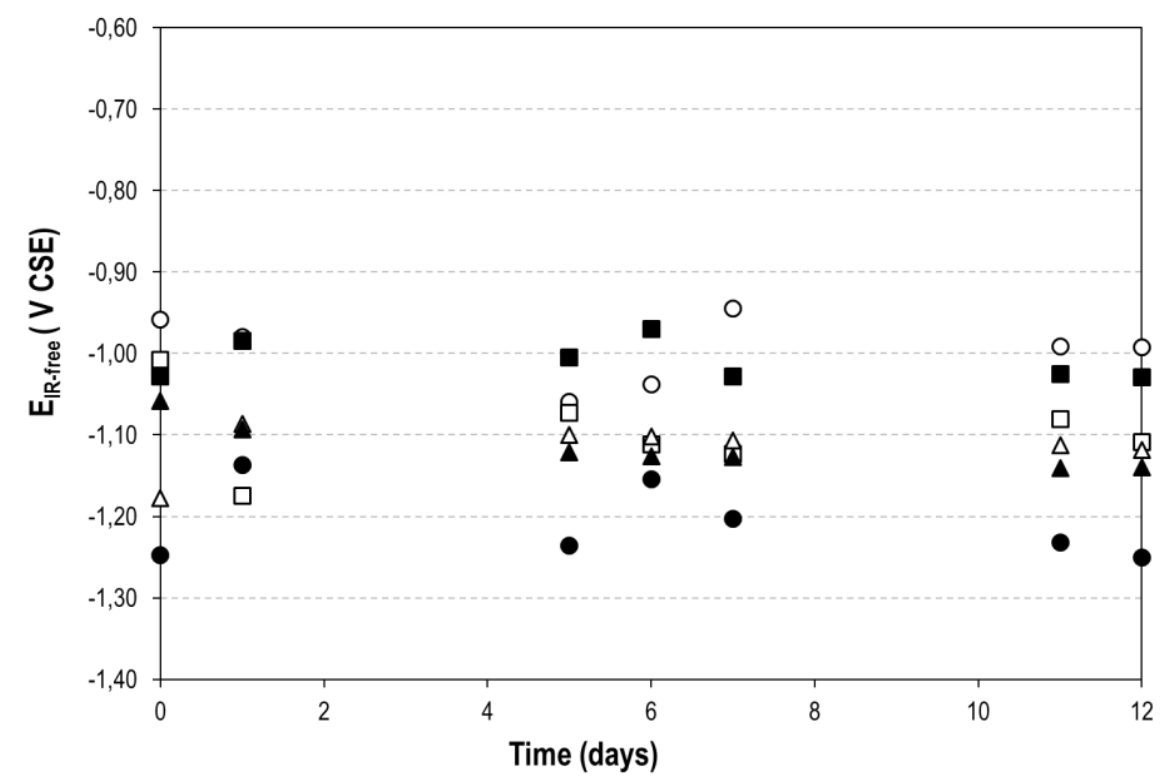

176 During the DC interference period, once a week the IR-free potential was recorded. Figures 7-10

177 show some examples of potential acquisition of steel specimens subjected to different levels of 178 interference. In the presence of $D C$ interference $0.1 \mathrm{~A} / \mathrm{m}^{2}$ a very small potential shift was recorded. 179 Recorded potential is not reported in the following graphs. Only the peak $1 \mathrm{~h}$ long showed $0.2 \mathrm{~V}$ 180 anodic polarization (Figure 10). During one-minute-long DC peaks were applied, IR-free potential 181 increased up to $-0.6 \mathrm{~V} \mathrm{CSE}$ and $0.8 \mathrm{~V}$ CSE in the presence of $1 \mathrm{~A} / \mathrm{m}^{2}$ and $10 \mathrm{~A} / \mathrm{m}^{2}$, respectively 182 (Figure 7). At longer peak duration, the anodic polarization reached highest values (Figures 8-9). It 183 should be noted that in the presence of $10 \mathrm{~A} / \mathrm{m}^{2}$, after the considerable initial potential increase, a 184 slow potential decrease over time was observed, mainly in tests at longer peak duration (Figure 10). 185 This trend confirmed what reported in [10]. 


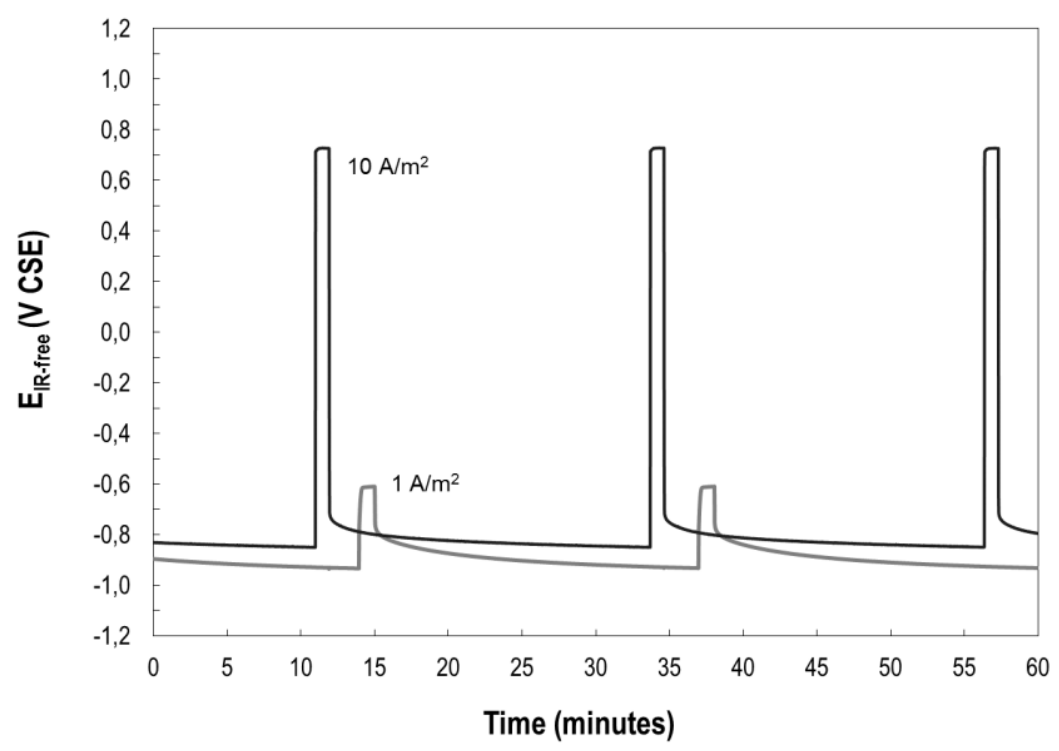

Figure 7 - IR-free potential profile during DC anodic peaks 1-minute long

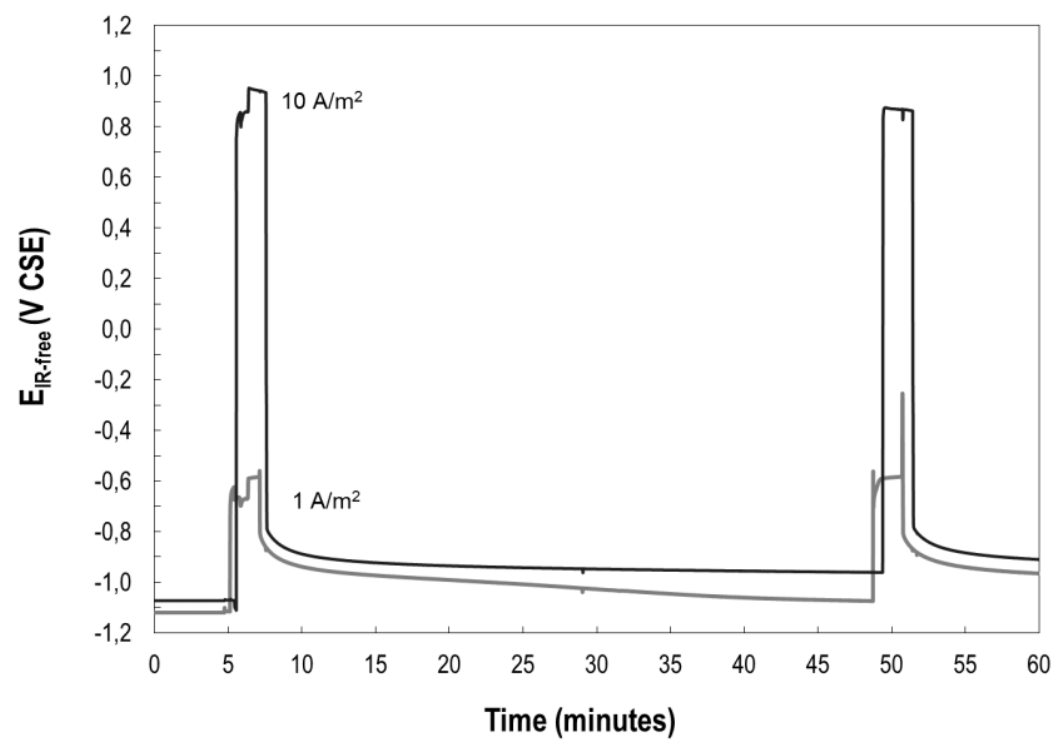

Figure 8 - IR-free potential profile during DC anodic peaks 2-minute long 190 


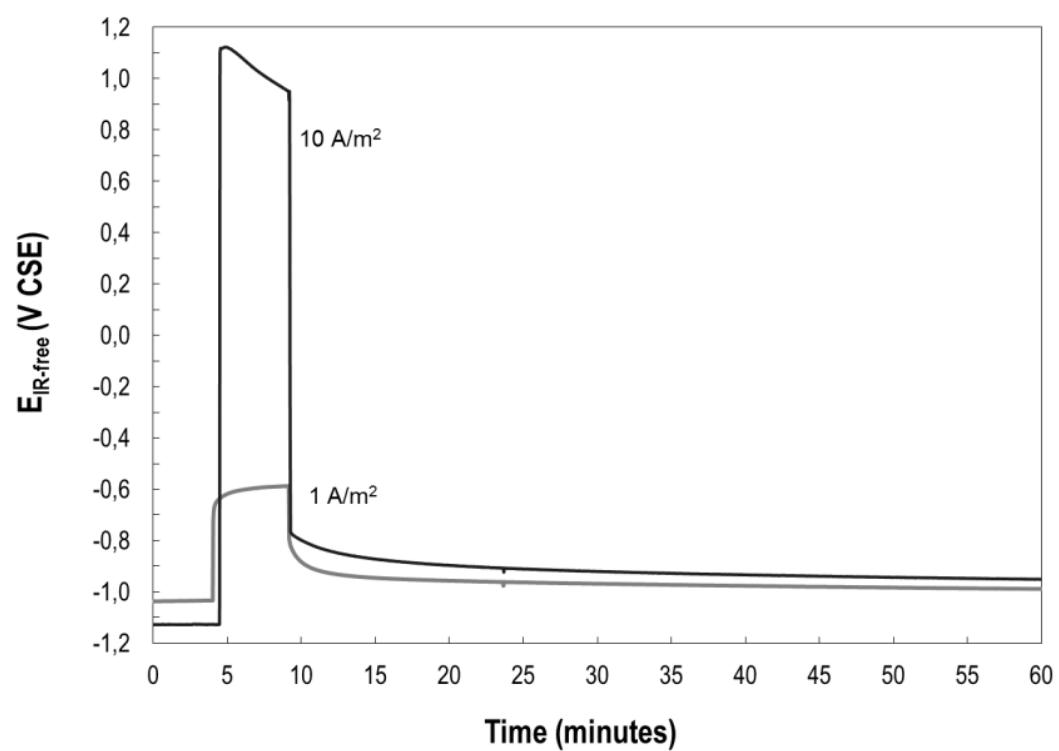

Figure 9 - IR-free potential profile during DC anodic peaks 10-minute long

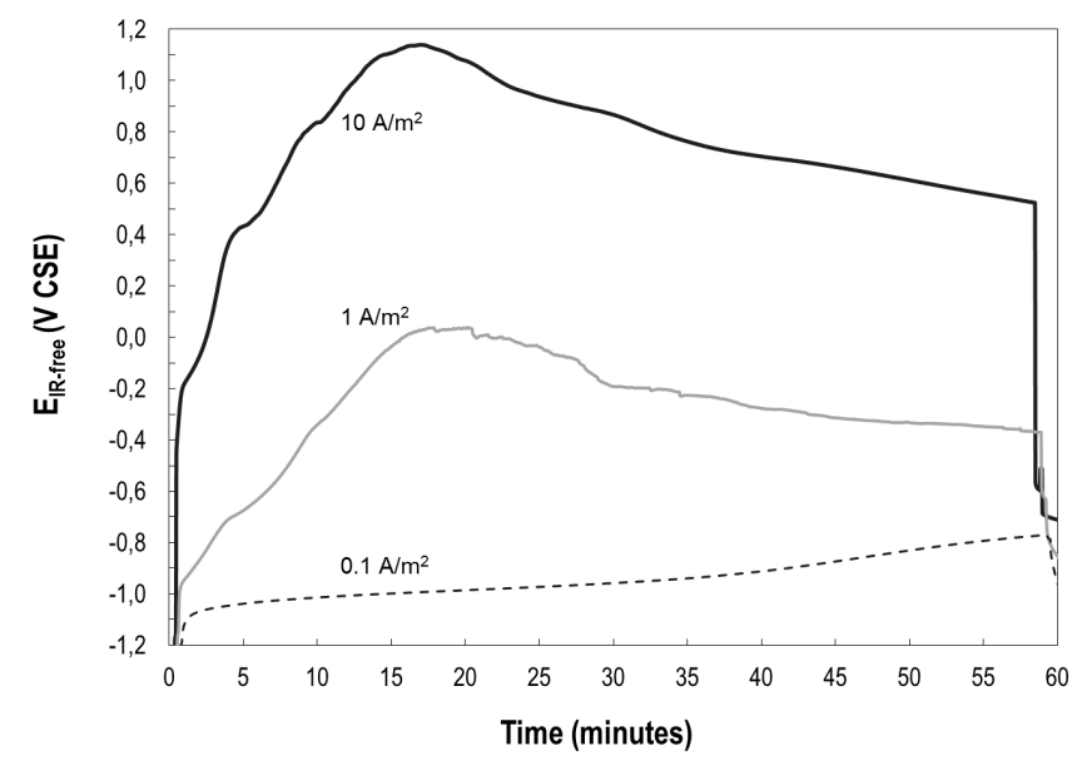

Figure 10 - IR-free potential profile during DC anodic peaks 1-hour long

196 Summarizing, once the interference is applied, a sudden potential shift towards more noble values

197 is recorded. Higher the applied DC interference, higher the potential shift:

198 - in the presence of $0.1 \mathrm{~A} / \mathrm{m}^{2} \mathrm{DC}$ interference the potential increase up to $-1.0 \mathrm{~V} \mathrm{CSE}$

- in the presence of $1 \mathrm{~A} / \mathrm{m}^{2} \mathrm{DC}$ interference potential as high as $-0.6 \mathrm{~V}$ CSE was recorded; potential increased up to $0 \mathrm{~V}$ CSE only during $1 \mathrm{~h}$ long peak 
- in the presence of $10 \mathrm{~A} / \mathrm{m}^{2} \mathrm{DC}$ interference, a strong increase of potential was recorded: maximum recorded value was close to $+1.2 \mathrm{~V}$ CSE.

203 At DC current density 1 and $10 \mathrm{~A} / \mathrm{m}^{2}$, the potential assumes values higher than the threshold value, $204-0.850$ V CSE (as provided by ISO 15589-1 [2]).

205 At the end of the peak, cathodic protection was re-applied; potential instantaneously decreases, 206 then a subsequent downward trend until protection level was reached.

207 It is important to state that potential readings under DC interference are not affected by the ohmic 208 drop due to the position of the tip of the Luggin capillary. In fact, ohmic drop, IR (in V), could be 209 roughly estimated as follow [1]:

$$
\mathrm{IR}=\rho \cdot d \cdot i
$$

where $\rho$ is resistivity (less than $20 \Omega \mathrm{m}$ in tested condition), $d$ is the distance between capillary tube

214 tip and carbon steel specimen $(=1 \mathrm{~mm}), i$ is the applied anodic current density. Accordingly, the 215 ohmic drop is $0.002 \mathrm{~V}, 0.02 \mathrm{~V}$ and $0.2 \mathrm{~V}$ in the presence of an anodic current density of $0,1 \mathrm{~A} / \mathrm{m}^{2}$, $2161 \mathrm{~A} / \mathrm{m}^{2}$ and $10 \mathrm{~A} / \mathrm{m}^{2}$, respectively. Only in the last case, ohmic drop has a minimum effect on 217 potential reading, even if the trend in potential variation is not strongly influenced. anodic interference $1 \mathrm{~h}$ long is negligible, lower than $10 \mu \mathrm{m} / \mathrm{y}$. Corrosion may be considered negligible also in the presence of an anodic DC interference $1 \mathrm{~A} / \mathrm{m}^{2}, 1$-minute long. In the presence 


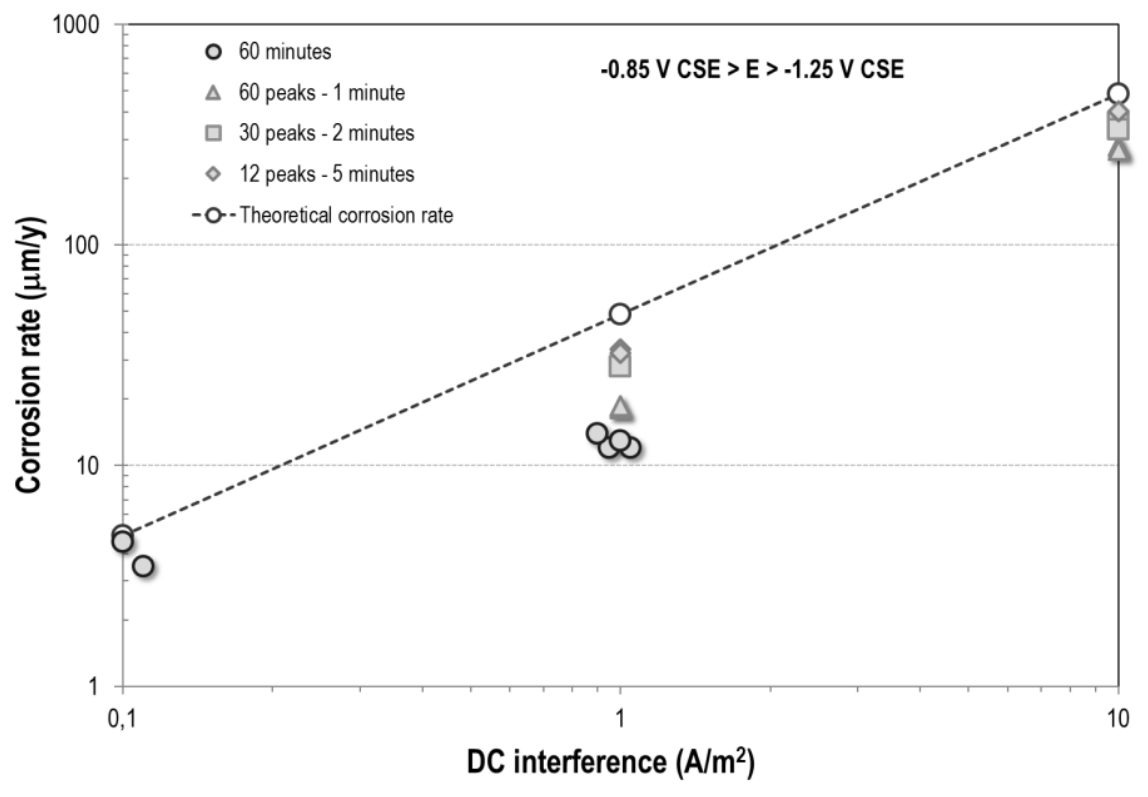

Figure 11 - Corrosion rate of cathodically protected carbon steel specimens

231 In Figure 11 theoretical corrosion rate, calculated by Faraday's law (Eq. 2), is also reported.

232 Measured corrosion rate is always lower than the theoretical value, confirming results reported in 233 [9].

234 It is possible to assume that during the anodic peak, the anodic current has initially to "neutralize" 235 the benefic effect of $\mathrm{CP}$, namely has to consume the alkalinity produced at the metal-to-soil 236 interface due to the cathodic reactions occurring at the metal surface. Then corrosion of metal may 237 occur. This point will be discussed later on.

238 As expected, at a constant anodic DC interference, measured corrosion rate increases with peak 239 duration, even if the increase is not directly proportional, as expected by Faraday's law, endorsing 240 the previous hypothesis regarding the presence of two different phases during the anodic peak: an 241 initial phase in which passivation is destroyed and a second phase of metallic corrosion. This point 242 will be discussed later on.

243 At a constant peak duration, higher is the anodic DC interference, more severe is the measured 244 corrosion rate. 


\section{Discussion}

4.1 Peak potential profile interpretation

247 During DC anodic interference a potential positive shift was measured on the cathodically polarized

248 carbon steel specimens. The potential increased about $0.2 \mathrm{~V}$ in the presence of $0.1 \mathrm{~A} / \mathrm{m}^{2}$, more than $2490.5 \mathrm{~V}$ in the presence of $1 \mathrm{~A} / \mathrm{m}^{2}$, even $1 \mathrm{~V}$ in the presence of $10 \mathrm{~A} / \mathrm{m}^{2}$. This anodic shift cannot be 250 explained considering the Tafel behaviour $(E-\log I)$ of active steel in soil. Figure 12 reports the Tafel 251 curve of carbon steel in soil simulating solution, obtained scanning the potential from $-0.2 \mathrm{~V}$ to +0.2 $252 \mathrm{~V}$ with respect the free corrosion potential at a scan rate of $10 \mathrm{mV} /$ minute. The Tafel slope of the 253 anodic part is about $60 \mathrm{mV} /$ decade. Accordingly, at the highest anodic DC current density $\left(10 \mathrm{~A} / \mathrm{m}^{2}\right)$ 254 the maximum potential shift should be in the range of $0.3 \mathrm{~V}$ from the protection condition; instead, 255 the measure potential shift was about $1 \mathrm{~V}$.

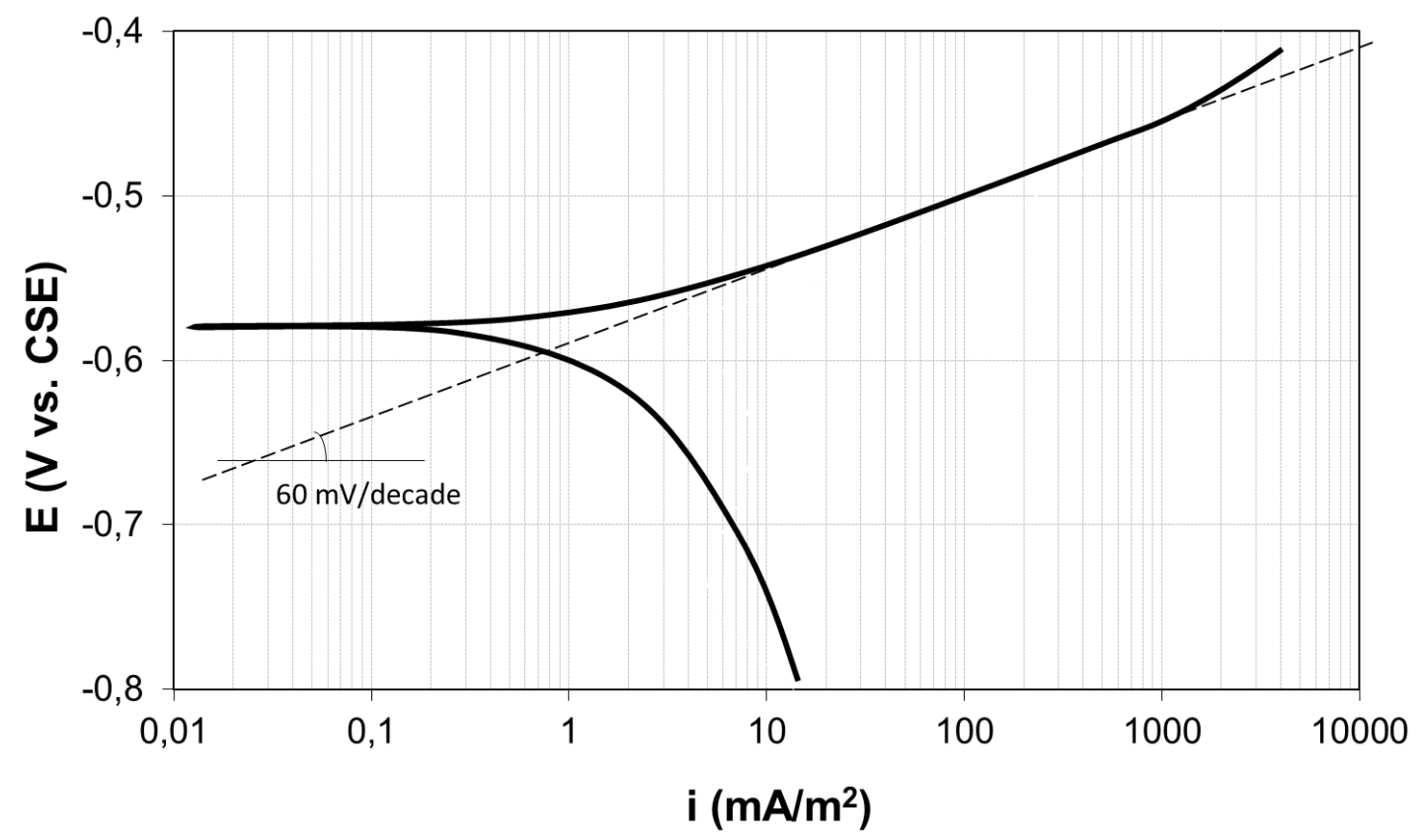

Figure 12 - Potentiodynamic polarization curve of carbon steel in soil-simulating solution

259 To interpret this high potential shift, it should be considered the different electrochemical behaviour 260 of carbon steel in CP condition. In fact, the presence of a cathodic process occurring on steel 261 surface before any DC interference deeply affects carbon steel corrosion behaviour. More precisely, 
cathodic reactions on steel in CP condition are oxygen reduction and hydrogen evolution,

263 depending on protection potential and current density:

The evolution of both reactions produces a significant $\mathrm{pH}$ increase at the steel-to-soil interface, also promoted by soil stagnant condition. The alkaline environment in contact with the metal $(\mathrm{pH}$ can increase up to 11 or higher, depending on cathodic current density [24]) has a beneficial effect on the metal as it promotes the formation of a passivity condition, as expected by iron Pourbaix diagram [25]. Then, carbon steel electrochemical behaviour under CP is typical of a passive 273 material.

274 The interruption of CP during the anodic DC interference does not remove instantly the alkalinity previously generated by the cathodic reactions on the steel: in other words, the residual alkalinity allows keeping steel in passive conditions even after the interruption of the cathodic current. Due to the presence of a passive film, carbon steel provides high resistance to current exchange, then justifying the initial high potential shifts recorded immediately after the anodic DC interference. Conversely, potential variations would be more contained on a carbon steel specimen in freely corroding condition, due to the absence of the passive film. Once the alkalinity is neutralized, potential decreases to values typical of active metal and anodic corrosion may occur. The period of passivation and corrosion will be discussed in the next paragraph. In the presence of severe anodic current density $\left(10 \mathrm{~A} / \mathrm{m}^{2}\right)$, potential reaches values that exceed the equilibrium potential of water dissociation reaction, which leads to oxygen evolution and local increase of acidity, according to the following reaction:

$$
2 \mathrm{H}_{2} \mathrm{O} \rightarrow \mathrm{O}_{2}+4 \mathrm{H}^{+}+2 \mathrm{e}^{-}
$$


289 The acidity produced by oxygen evolution reaction (Eq. 5) contributes to quickly neutralize the

290 residual alkalinity produced by CP, weakening the passivity of steel; a decrease of potential

291 (confirmed by potential readings, Figures 9 and 10) is measured in a shorten period. Once the

292 passivation is destroyed, steel corrosion starts at a corrosion rate expected by Faraday's law.

$293 \quad 4.2 \quad$ Passivation and anodic corrosion during an anodic peak

294 It has been demonstrated that measured corrosion rate of cathodically polarized carbon steel

295 specimens exposed to anodic DC interference are always lower than the theoretical value estimated

296 through the Faraday's law.

297 Due to the electrochemical behavior of carbon steel in CP condition, it is possible to assume that 298 during each anodic peak, two phases may be identified (Figure 13):

299 - phase 1 - time in passivity $\left(t_{0}-t_{\text {passivity }}\right)$ : the anodic current initially "neutralizes" the benefic 300 effect of $\mathrm{CP}$, namely consumes the alkalinity produced at the metal-to-soil interface due to 301

- phase 2 - time in corrosion $\left(t_{\text {passivy }}-t_{\text {peak }}\right)$ : once the alkalinity is neutralized, then anodic current may corrode the metal according to the Faraday's law.

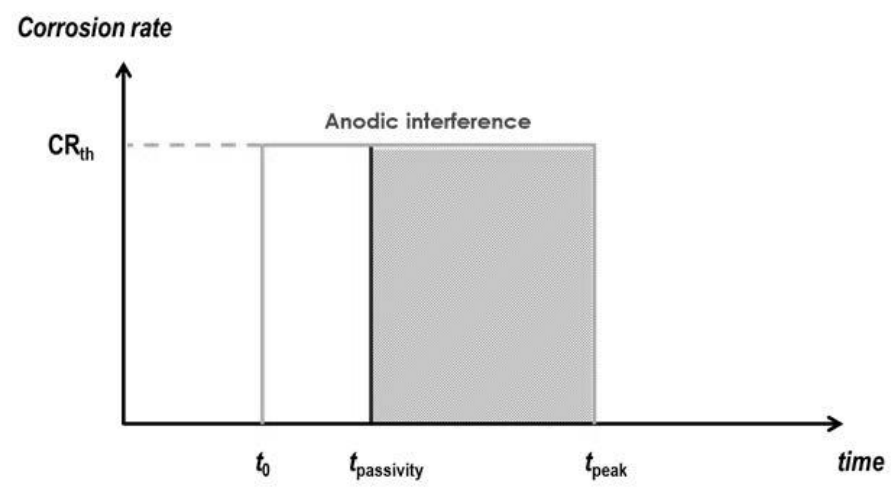

307 Before $t_{0}$ and after $t_{\text {peak }}$, carbon steel is cathodically protected, then corrosion is nil. During the peak,

308 in phase 1 corrosion rate is still zero, while after $t_{\text {passivity }}$ (phase 2) corrosion rate equals the 309 maximum expected corrosion rate according to Faraday's law, $C R_{\mathrm{th}}$. 
311 Taking $t_{0}=0$, the following applies:

312

313

$$
C R_{\text {th }} \cdot\left(t_{\text {peak }}-t_{\text {passivity }}\right)=C R_{\text {exp }} \cdot\left(t_{\text {peak }}\right)
$$

314 where $C R_{\exp }$ is the measured corrosion rate. The time in $t_{\text {passivity }}$ may be calculated as follow:

$$
t_{\text {passivity }}=t_{\text {peak }} \cdot\left(1-\frac{C R_{\text {exp }}}{C R_{t h}}\right)
$$

318 Duration of phases 1 and 2 are reported in Figure 14. Table 2 summarizes the percentage of 319 maintenance in each phase. For each tested condition, the percentage has been calculated as the 320 ratio between the time in passivation (or in corrosion) as reported in Figure 13 over the total duration 321 of the peak.

322 The following can be drawn:

323 - at a constant DC current density, both the time in passivation and time in corrosion increase 324 with increasing peak duration, the latter in a more predominant way

325 - at a constant peak duration peak, the higher the anodic DC interference, the lower the time in passivation, the higher the time in corrosion

- the time in which the passive film is stable is proportional to the duration of cathodic protection, which is greater for the specimens subjected to $1 \mathrm{~h}$ and 5 minutes of interference. 

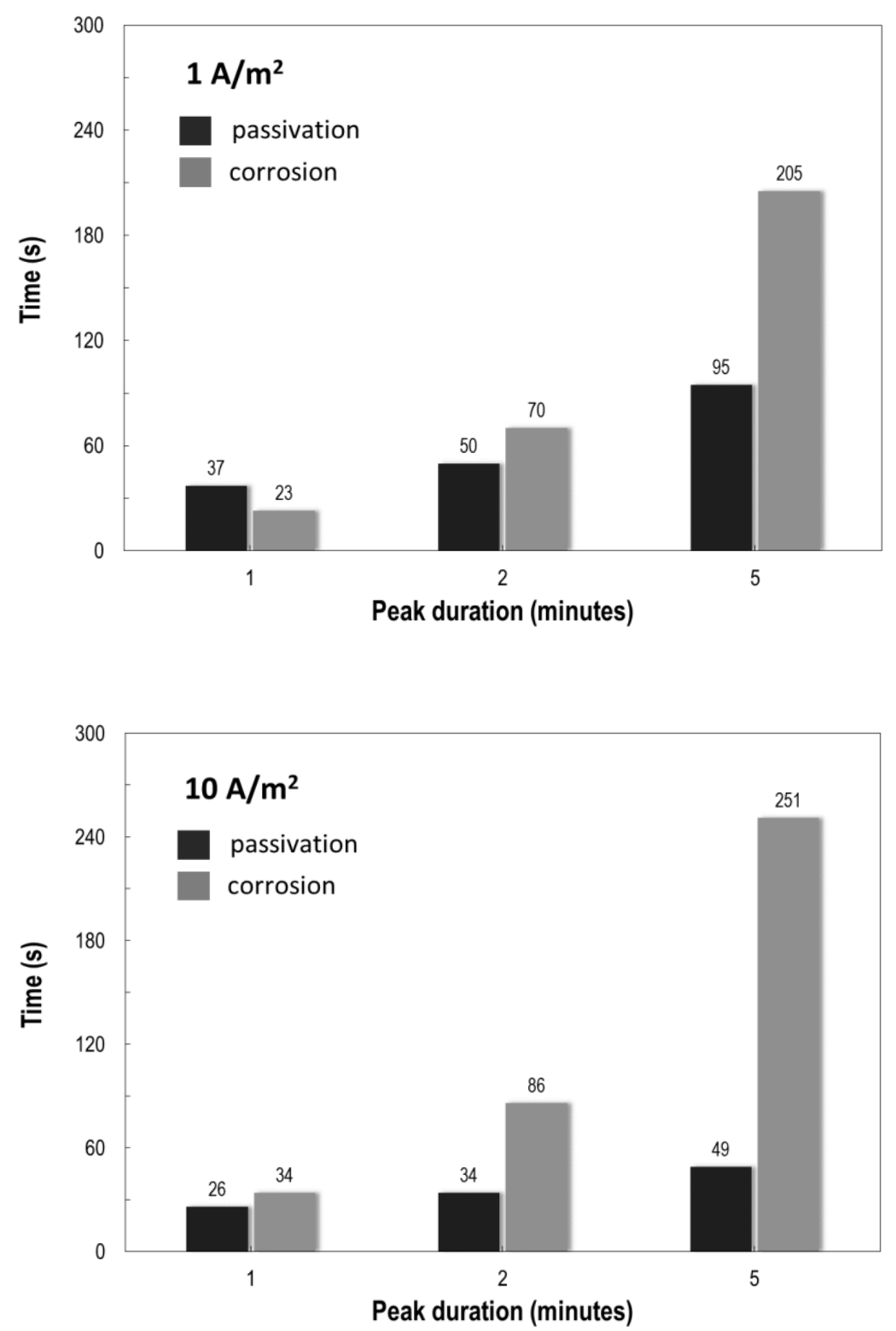

Figure 14 - Time in passivity and time in corrosion during each DC anodic peak

Table 2 - Percentage of time in passivity and time in corrosion

\begin{tabular}{cccc}
\hline $\begin{array}{c}\text { DC anodic current } \\
\text { density }\left(\mathbf{A} / \mathbf{m}^{2}\right)\end{array}$ & $\begin{array}{c}\text { Peak duration } \\
\text { (minutes) }\end{array}$ & Time in passivation & Time in corrosion \\
\hline \multirow{3}{*}{1} & 1 & $62 \%$ & $38 \%$ \\
\cline { 2 - 4 } & 2 & $42 \%$ & $58 \%$ \\
\cline { 2 - 4 } & 5 & $32 \%$ & $68 \%$ \\
\hline \multirow{3}{*}{10} & 60 & $11 \%$ & $89 \%$ \\
\hline & 1 & $43 \%$ & $57 \%$ \\
& 2 & $28 \%$ & $72 \%$ \\
\hline & 5 & $16 \%$ & $84 \%$ \\
\hline & 60 & $10 \%$ & $90 \%$ \\
\hline
\end{tabular}




\section{Conclusions}

Weight loss tests were carried out in soil-simulating environment on cathodically protected carbon steel specimens varying the $D C$ interference $\left(0.1,1\right.$ and $\left.10 \mathrm{~A} / \mathrm{m}^{2}\right)$ and the peak duration. Laboratory experimental results allow to state:

- potential readings confirm the formation of passive condition on steel under CP condition, due to the alkalinity produced by oxygen reduction and hydrogen evolution reactions;

- during a DC anodic peak, initially the anodic reaction occurring on the metal causes the progressive neutralization of electrolyte alkalinity in contact with steel with loss of passive condition; then anodic corrosion occurs;

- a potential increase was measured during each anodic peak: the potential shift was higher than what expected by Tafel Law;

- consequently, potential peak cannot be considered a parameter to evaluate the risk of DC interference on a cathodically protected specimens;

- peak duration and DC peak intensity are the key parameters:

- a daily peak $1 \mathrm{~h}$ long is acceptable provided the anodic $\mathrm{DC}$ is lower than $1 \mathrm{~A} / \mathrm{m}^{2}$;

- peak few-minute-long are acceptable, provided the total anodic duration is $1 \mathrm{~h}$ per day and the maximum DC intensity is in the range of $1 \mathrm{~A} / \mathrm{m}^{2}$;

0 if anodic current density is close to $10 \mathrm{~A} / \mathrm{m}^{2}$, any interference duration is not acceptable.

The raw/processed data required to reproduce these findings cannot be shared at this time as the data also forms part of an ongoing study.

\section{References}

359 [1]. L. Lazzari, P. Pedeferri, Cathodic protection, $1^{\text {st }}$ ed., Milan, Italy, Polipress, 2006. 
360 [2]. ISO 15589-1, Petroleum, petrochemical and natural gas industries - Cathodic protection of pipeline systems - Part 1: On-land pipelines, International Standard Organization, Ch. de Blandonnet 8, $\mathrm{CH}-1214$ Vernier, Geneva, Switzerland.

[3]. M. Barbalat, D. Caron, L. Lanarde, M. Meyer, S. Fontaine, F. Castillon, J. Vittonato, P. Refait, determination of residual corrosion rates under cathodic protection, Corrosion Science 55 (2012) 246-253.

[4]. M. Barbalat, D. Caron, L. Lanarde, M. Meyer, S. Fontaine, F. Castillon, J. Vittonato, P. Refait, Estimation of residual corrosion rates of steel under cathodic protection in soils via voltammetry, Corrosion Science, 73 (2013) 222-229.

[5]. C. Wen, J. Li, S. Wang, Y. Yang, Experimental study on stray current corrosion of coated pipeline steel, Journal of Natural Gas Science and Engineering 27 (2015) 1555-1561.

[6]. Q. Liu, W. Wu, Y. Pan, Z.Y. Liu, X.C. Zhou, X.G. Li, Electrochemical mechanism of stress corrosion cracking of API X70 pipeline steel under different AC frequencies, Construction and Building Materials 171 (2018) 622-633.

[7]. S.R. Allahkaram, M. Isakhani-Zakaria, M. Derakhshani, M. Samadian, H. Sharifi-Rasaey, A. Razmjoo, Investigation on corrosion rate and a novel corrosion criterion for gas pipelines affected by dynamic stray current, Journal of Natural Gas Science and Engineering 26 (2015) 453-460

[8]. N. Birbilis, L.J. Holloway, M. Forsyth, Simulated transient loss of cathodic protection for buried pipelines, Corrosion, 61 (2005) 498-501.

[9]. Y. Huo, M.YJ. Tan, Measuring and understanding the critical duration and amplitude of anodic transients, Corrosion engineering, science and technology (2017) 1-8.

[10]. S. Qian, Y.F. Cheng, Accelerated corrosion of pipeline steel and reduced cathodic protection effectiveness under direct current interference, Construction and Building Materials 148 (2017) 675-685. 
[11]. M. Ormellese, L. Lazzari, S. Goidanich, S. Sesia, CP criteria assessment in the presence of AC interference, NACE International Corrosion Conference Series 2008, Pages 08064010806410, Corrosion 2008; New Orleans, LO; United States.

[12]. M. Ormellese, S. Goidanich, L. Lazzari, Effect of AC interference on cathodic protection monitoring, Corrosion Engineering, Science and Technology, 46 (2011) 618-623.

[13]. Z. Jiang, Y. Du, M. Lu, Y. Zhang, D. Tang, L. Dong, New findings on the factors accelerating AC corrosion of buried pipeline, Corrosion Science, 81 (2014) 1-10.

[14]. ISO 18086, Corrosion of metals and alloys. Determination of AC corrosion. Protection criteria, International Standard Organization, Ch. de Blandonnet 8, CH-1214 Vernier, Geneva, Switzerland.

[15]. EN 50162, Protection against corrosion by stray current from direct current systems, Brussels, Belgium; European Committee of Standardization.

[16]. NACE SP0169, Control of external corrosion on underground or submerged metallic piping systems, NACE International, Houston, TX.

[17]. L.Y. Xu, Y.F. Cheng, Experimental and numerical studies of effectiveness of cathodic protection at corrosion defects on pipelines, Corrosion Science, 78 (2014) 162-171.

[18]. U. Angst, M. Büchler, B. Martin, H.-G. Schöneich, G. Haynes, S. Leeds, F. Kajiyama, Cathodic protection of soil buried steel pipelines - a critical discussion of protection criteria and threshold values, Materials and Corrosion 67 (2016) 1135-1142.

[19]. R.A. Gummow, P. Eng, GIC effects on pipeline corrosion and corrosion control systems, Journal of Atmospheric and Solar-Terrestrial Physics 64 (2002) 1755 - 1764

[20]. A. Brenna, M. Ormellese, L. Lazzari, Effects of intermittent DC stray current on carbon steel under cathodic protection, NACE International Corrosion Conference Series 2015, Corrosion 2015; Dallas, TX; United States.

[21]. EN 10208, Steel pipes for pipelines for combustible fluids, Brussels, Belgium, European Committee of Standardization.

[22]. API 5L, Specification for line pipe, American Petroleum Institute (API), 1220 L St., N.W., Washington, DC 20005-4070. 
414 [23]. ASTM G1, Standard practice for preparing, cleaning, and evaluating corrosion test specimens, 415 West Conshohocken, PA: ASTM International, American Society for Testing Materials (ASTM 416 International), 100 Barr Harbor Drive, PO Box C700, West Conshohocken, PA, 19428-2959. 417 [24]. R. Kodym, D. Snita, V. Fíla, K. Bouzek, M. Kouril, Investigation of processes occurring at $418 \quad$ cathodically protected underground installations: Experimental study of $\mathrm{pH}$ alteration and 419 mathematical modeling of oxygen transport in soil, Corrosion Science, 120 (2017) 14-27.

420 [25]. M. Pourbaix, Atlas of electrochemical equilibria in aqueous solutions, $2^{\text {nd }}$ ed., ISBN: 0915567989, NACE Cebelcor, Houston, TX, 1974. 